\title{
Diffusion of Sustainable Construction Practices. A Case of International Cooperation
}

\author{
Andrea Giachetta, Katia Perini, Adriano Magliocco \\ Department of Architectural Sciences, University of Genoa, Genoa, Italy \\ Email: andreagiachetta@arch.unige.it, katiaperini@hotmail.com,magliocc@arch.unige.it
}

Received January 27, 2013; revised February 28, 2013; accepted March 11, 2013

\begin{abstract}
Data shows that buildings play an important role in the field of energy efficiency and environmental sustainability. The exchange of information among different countries is a key element to promote a wider diffusion of practices for sustainable development in the fields of architecture and urban planning, contributing to the improvement of new skills and economic and production activities, while also reducing the environmental impact of construction on the territory. An international cooperation can lead an exchange of experiences and practices, which could play a fundamental role since countries can have similar problems to deal with, as it happens for the specific identity of the Mediterranean territory in coastal and rural areas. This paper analyses a case of international cooperation, the project SCORE, "Sustainable COnstruction in Rural and fragile areas for energy Efficiency", financed under the European MED Programme with the purpose to promote sustainable energy policies in the construction sector on fragile coastal and rural Mediterranean areas.
\end{abstract}

Keywords: Sustainable Construction; Energy Efficiency; International Cooperation; Mediterranean Areas

\section{Introduction}

In the last few years the attention towards the environment seems to have become one of the primary objectives to follow. Data shows that constructions play an important role in the field of sustainability. In industrialized countries, buildings represent $\pm 40 \%$ of the energy used [1]. Buildings consume a significant amount of energy over their life-time; the energy consumption of these in Europe is about $40 \%$ of the total energy demand [2]. They generate $40 \%-50 \%$ of the total output of greenhouse gases [3]. The building sector has one of the greatest impacts on the environment. This is caused by several variables, which are mainly related to: exploitation of non renewable material resources, indiscriminate use of the territory, highenergy consumption connected to the whole life cycle, and air pollution production [4].

The growing importance of what could be called environmentalism is, nowadays, leading to the formation of contrasts with respect to different approaches to this field; while, up to a few years ago, the argument was between the supporters of more awareness actions on the environment and the ones uninterested in this field, which considered the topic not interesting. In this period the same environmentalists are against some projects defined as "sustainable" or to the installation of energy production systems from renewable source, for the territory eco-system and landscape preservation [5].
To promote a sustainable approach to the planning and implementation of construction activities and urban and building renovation, diffusion activities are needed. An international cooperation can lead an exchange of experiences and practices, which could play a fundamental role since countries can have similar problems to deal with. This happens for the specific identity of the Mediterranean territory in coastal and rural areas. These areas are of great interest for their history, culture, landscape and nature, but are also extremely fragile if we consider the possible impact of human activities and the creation of infrastructures and residential, touristic and production sites, but also the impact of ports and agricultural activities [6].

The exchange of information among different countries is a key element to promote a wider diffusion of practices for sustainable development in the fields of architecture and urban planning, contributing to the improvement of new skills and economic and production activities, while also reducing the environmental impact of construction on the territory $[7,8]$.

This paper analyses a case of international cooperation: the objectives, development, and results of the project SCORE, "Sustainable COnstruction in Rural and fragile areas for energy Efficiency". This project has been financed under the European MED Programme with the purpose to promote sustainable energy policies in the 
construction sector on fragile coastal and rural Mediterranean areas. The MED Programme is a transnational programme of European territorial cooperation. It is financed by the European Union as an instrument of its regional policy. The transnational setup allows the programme to tackle territorial challenges beyond national boundaries [7]. Starting from a brief description of the main objectives and partners (from different countries) involved, the article discusses the main methods, tools, and results of the SCORE project.

\section{The Project SCORE}

The project SCORE, "Sustainable COnstruction in Rural and fragile areas for energy Efficiency", is a European project financed under the European MED Programme [8]. The main goal of the project is to implement sustainable energy policies in the construction sector on fragile coastal and rural MED areas with exceptional landscape values exploiting eco-innovative potential, using traditional building elements combined with innovative green technologies.

The Province of Savona (in Liguria Region, Italy) is the leader partner of the project working with other ten partners from seven different countries: Cyprus, France, Greece, Italy, Portugal, Slovenia, and Spain. The partners involved regional agencies for energy, chambers of commerce and their relevant bodies have previous experiences of territorial management aimed at adopting sustainable development strategies and research experiences in the field of environmental sustainability.

SCORE, thanks to the collaboration of partners from different countries with similar territorial characteristics, aims at recording, selecting, organising and spreading the knowledge of good practices which are common to the partners involved, when dealing with issues such as the architectural integration of technologies and systems for energy production out of renewable sources, the reducetion of polluting emissions, the protection of the environment and the health of the population.

The project does not mean to simply focus the attention on well-known sustainable strategies for construction design and building activities, but to assess the best methods for an effective implementation of the mentioned strategies, with reference to the building tradition and the local normative and productive framework, considering the continuous education of operators and companies.

With the purpose to effectively identifying the best practices for sustainable development and promote their implementation, the project SCORE deals with the direct application with the different local stakeholders of the building sector and the citizens, as the ones who want to protect the environment and its resources, or with the associations who represent their claims. The Project is based both on the profitable exchange of knowledge among the participant countries and on organising local focus groups aimed at creating a stakeholders network in the respective territories. For an international exchange and also to involve local stakeholders the most effective tool is Internet; therefore the project has a website, www. scoremed.eu, which is one of the intended results of the Project itself and effectively presents SCORE and its initiatives (Figure 1).

\section{Normative Framework and Case Studies}

Within the SCORE project the different Partners identified the normative framework applicable to the project at national and local level, in order to compare it with other countries. If the framework of European Directives ensures a certain uniformity of the normative in different countries, local implementation regulations can significantly vary, providing a different effectiveness and flexibility for territorial management tools. Since these regulations play a fundamental role in the dissemination of technologies and systems for the planning and construction of sustainable buildings, it is important to compare the impact they can have on the different territories where they apply in order to asses the need for amendments or integrations; this has to be taken into account since SCORE partners are public entities with decisional power, if not direct competence, in the drafting of this regulations.

Another important action implemented by the different partners in order to compare the best results achieved at local level by current norms and regulations was the identification of case studies to highlight the best local practices concerning the architectural integration of sustainable technologies and systems. Several Case Studies were identified, included in a special section of the website and classified according to specific keywords (Figure 2). They mainly refer to building complexes and existing buildings, located in the different territories of the partner countries involved, where particular relevance is given to factors such as: the adoption of bioclimatic strategies, the integration of particular installations, the adoption of solutions to reduce energy consumption or, again, the use of natural materials, management strategies for environmental resources, correct integration with the existing natural and anthropic context. These case studies come from heterogeneous experiences referred to settlements of various sizes (from single houses to entire districts), to buildings with different destination for use (housing, tourism, production), in different contexts (urban areas, ports, agricultural areas, mountains), newly built or resulting from the renovation of existing buildings, both modern or with an historical value. The project also covers case studies of a different nature concerning, for instance, specific didactic experiences on 


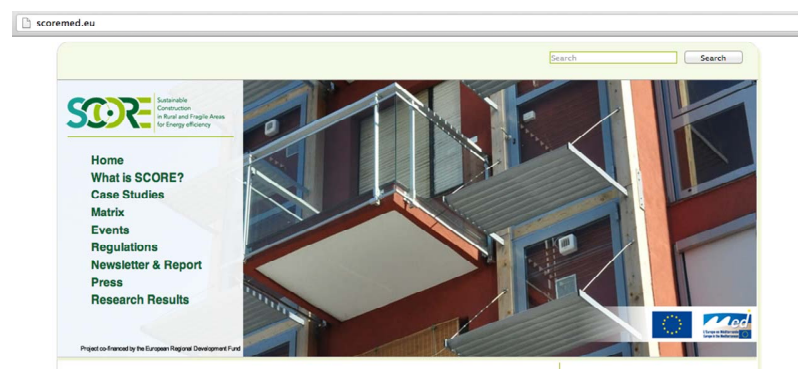

Figure 1. SCORE web-site home page [8].
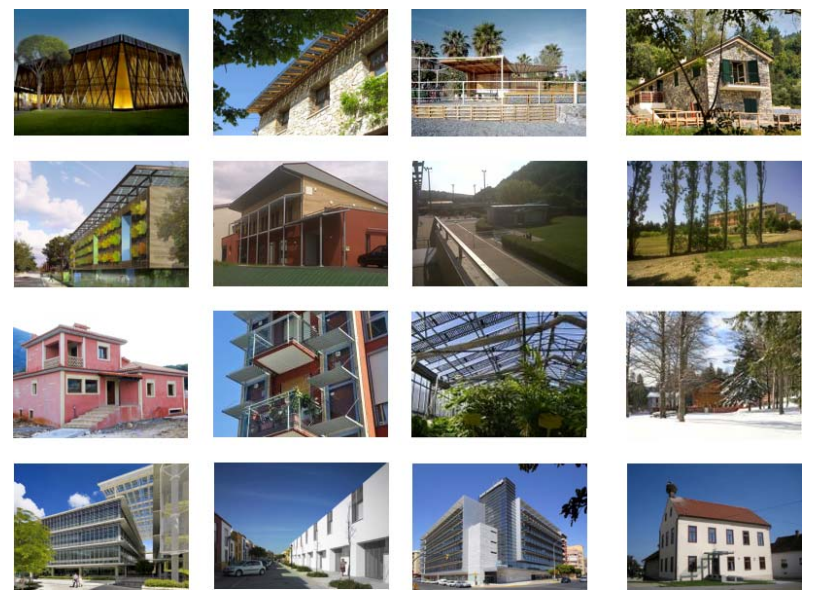

Figure 2. Some of the case studies analysed within SCORE project [8].

sustainability for future designers based on learning by doing approach (Figure 2, first line, third image), or local environmental certification systems for buildings. For example the first photograph (Figure 2) shows the new Mazan community centre. This French project is based on the integration of biocompatible materials and skin solutions, with a minimum amount of sophisticated effects (simple and natural) and materials. This is an ecofriendly project that meets demanding standards and provides an answer to the issues facing the environment and society. A strong feature of the project is the will to reduce energy consumption in the production and shipping of construction materials as well as the development of local production channels. This project makes considerable use of three local resources: wood, straw, and gypsum. Resorting to straw-bales as the main insulating material rather than the other industrially produced insulating materials has a number of benefits for the environment. Indeed, this is a material that enables the local value of a renewable natural resource, contributing also to the fight against greenhouse gases, as it is a material that stores $\mathrm{CO}_{2}$ and has very useful thermal properties [8].

An interesting case study coming from Italy is the "Double purpose greenhouse", based on the use of renewable energy (Figure 2, third line, third photograph).
The work consists of an installation of semi-transparent photovoltaic panels on greenhouses. The study aims at testing the sustainability and the effectiveness of a "double purpose" greenhouse, which could produce more energy than the amount consumed, without impairing productive capacity and use flexibility. Results obtained show that no significant reduction of the productivity of plans grown is observed (both from a quantitative and a qualitative point of view) replacing $20 \%$ of the total surface originally covered by glasses with photovoltaic panels. The photovoltaic surface is almost $50 \mathrm{~m}^{2}$ for a production of $4.1 \mathrm{KWp}$. The photovoltaic system fulfils about $40 \%$ of electric requirement of greenhouse (about $9.100 \mathrm{~m}^{2}$ of indoor surface; [8]).

The third photograph in the last line of Figure 2 is the Case study "Hotel Monte Malaga” (Spain). Monte Malaga is a modern and emblematic building due not only to its innovative design but also because it is an example of sustainable construction. According to the Andalusian Energy Agency, the big hotels with a proper use of energy saving measures can save up to $30 \%$ of primary energy. The Hotel Monte Málaga is the first hotel in Spain that integrates a cogeneration power center and bioclimatic principles. It is a huge generator of clean energy using solar thermal and solar photovoltaic, integrated into its architecture. The applications of current technologies for saving and clean energy generation are combined with traditional Mediterranean strategies as shade and natural ventilation. Bioclimatic criteria of sunlight, insulation and ventilation (energy saving), along with cleaner production of energy (photovoltaic and thermal), represent a real bet for a new and more respectful relationship between the hotel building and its environment [8].

One or more tags or categories (which can be assigned at same time to the projects) identify the case studies, these are:

- renewable energy;

- solar energy;

- photovoltaic;

- biocompatible materials;

- natural control strategy;

- thermal collector;

- skin solutions;

- biomass/biogas;

- passive;

- efficient management;

- geothermal gradient.

Several cards describe and critically analyse the case studies, highlighting the transfer potential of the adopted methodologies and strategies, which is a key element within the scope of the SCORE project.

This approach allowed the different partners to gain knowledge of interesting urban and construction activi- 
ties in similar areas of other countries and to discover some situations of great interest within their own territory that were still relatively unknown and which deserved, however, to be promoted due to their innovative features.

The analysis and comparison of local norms and regulations and of the case studies allowed the identification of the main components, elements or construction materials, of design strategies and technological systems which become the focus for further phases of the project with regard to different possible implementation cases (ex-novo or on existing buildings) available in the respective territories.

\section{Focus Groups as Tool to Elaborate Strategies of Governance}

In the identification of case studies and of the issues connected to the implementation of norms and regulations by different stakeholders in the building process, described above, (designers, builders, suppliers of raw materials, building systems and plants, resellers and engineers working with these systems) local focus groups played a fundamental role. These are indeed a series of meetings (conferences, roundtables, workshops) held locally by different SCORE partners. These involved, in order to provide a positive opportunity for confrontation, the above-mentioned stakeholders of the construction sector together with local authorities, training and research institutes, universities and environmental associations. Thanks to the focus groups meetings SCORE and its several phases of development have been presented, thus providing the above-mentioned possibility to identify some case-studies, still unknown to the SCORE partners, but also to point out specific issues common interest highlighted by the SCORE project.

The leader partner province of Savona, for instance, through a series of interviews with market operators and trade associations could highlight some communication issues among manufacturer, designers and installers and local authorities and with respect to the interpretation of some legal requirements for promoting photovoltaic systems integrated into architectural structures in Liguria (Italian region on the Mediterranean seaside). This is one the regions with the lower number of photovoltaic installations in a country that, in the last few years, became a world leader in this branch. According to the "Rapporto statistico 2011 Fotovoltaico" of the GSE (the Energy Service Management of the Ministry for Economy and Finance) [9], Italy is the second nation in the world for installed capacity. Difficulties mainly concerned the lack of communication between operators. Therefore, one of the SCORE focuses ("Integrated Photovoltaic: opportunities and difficulties in spreading the application in Liguria”) of the Province of Savona concentrate on this topic to start setting up municipal strategies to tackle relevant problems. This involved representatives of the University of Genoa, of professional associations, manufacturer of photovoltaic modules and experts of the province and municipal authorities, of CeRSAA (Regional Center for Research and Agricultural Support, because of the prospective integration of photovoltaic solutions on greenhouses and agricultural land) and of Legambiente Liguria.

The focus groups represented an opportunity to effectively face specific problems and analyse the limits to the dissemination of these systems and technologies and find the best possible solutions. The creation of a network of stakeholders with shared interests and competences achieved through the focus groups plays also a fundamental role for disseminating project results.

\section{An Eco-Construction Tool: SCORE Matrix}

The analysis of norms and case-studies, as well as the local focus groups, allowed each SCORE partner to select building systems and technologies with high energy and environmental efficiency already in use or potentially available or suitable for development and diffusion in their own territory, while taking into account the historical-environmental value and fragile landscape of coastal and rural areas.

After highlighting these systems and technologies, a tool (defined as "eco-construction too l" in the project) has been developed; this has been realized to be userfriendly for the operators of the local network and to represent an effective model for the assessment, comparison and transfer of information among different partners. This process leaded to the development of the "Matrixes", which are developed by each partner starting from a common scheme to ensure a constant confrontation with each other.

The systems and technologies identified are: aggregation and exposure systems of the settlements for natural climatic control; passive solar Systems; thermal solar systems; photovoltaic systems; mini-micro wind-power systems; biomasses; geothermal systems, shading devices, natural ventilation; natural lighting; automatic control systems (smart buildings); coating systems (hyperinsulation and use of phase-change materials, PCM); eco-friendly materials; use of vegetation for microclimatic control; water management. The possible applications/declinations are: new constructions; renovation of recent buildings; recovery/renovation of historical buildings; ex-novo activities in historical contexts, as shown in Figure 3.

The various systems and technologies are cross-evaluated in each matrix together with possible implementations (i.e.: passive solar systems for the refitting of recent 


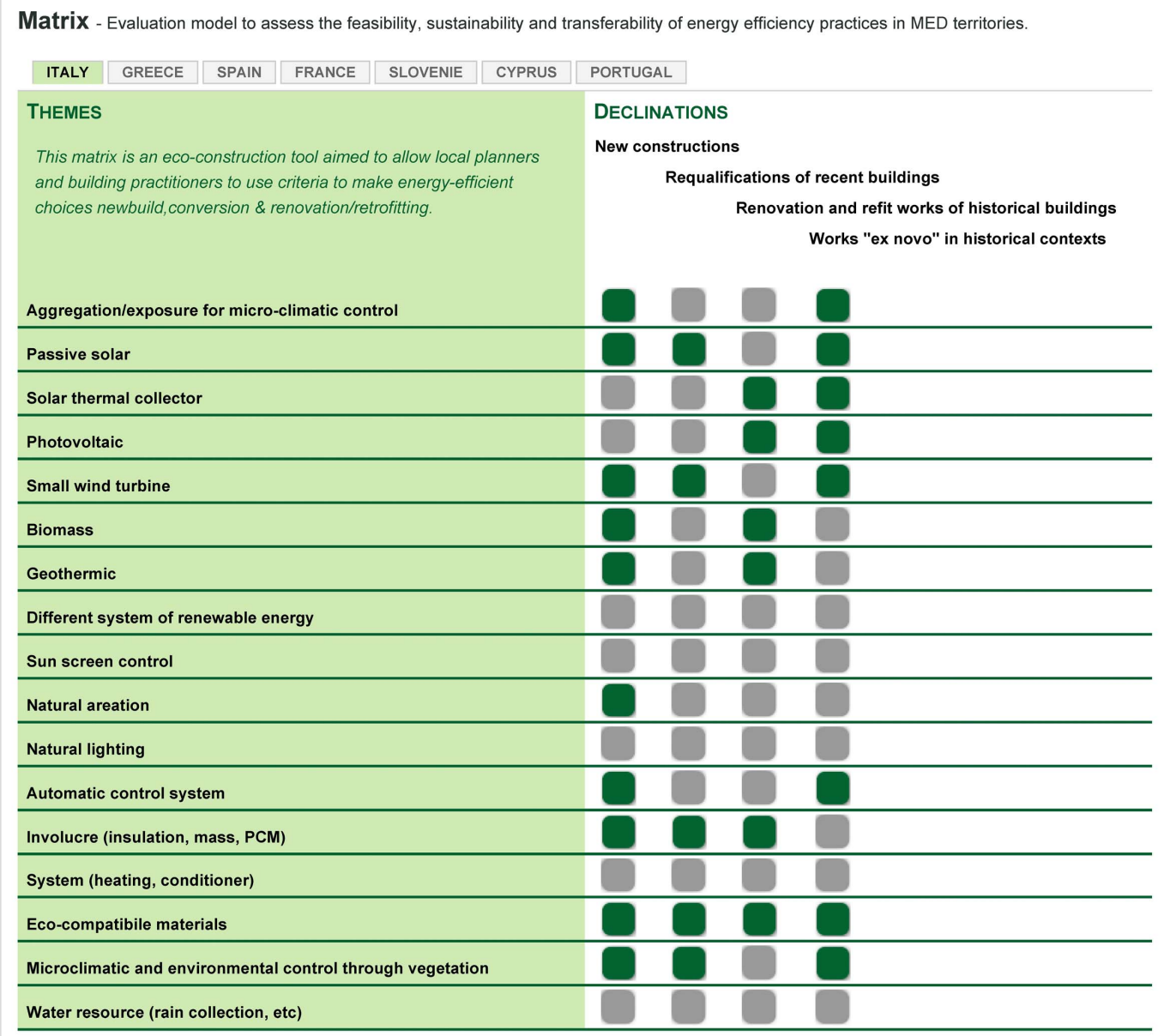

The SCORE project is co-financed by the European Regional Development Fund in the framework of the MED Programme - Privacy policy - Contact

Figure 3. SCORE matrix [8].

buildings). Each partner then worked on specific documents containing analysis and proposals on the mostrelevant cross-points, available for download from the project website in the language of each partner (for better understanding by local network operators) and with an English abstract (for international comparison). This provides a short description of the system and technology (with reference to the specific context and the state of implementation considered case by case), analysis of case-studies, relevant norms and regulations, with their possible critical evaluation in the annex, an evaluation of the relations with the local building history, the identification of strengths and advantages of the relevant system and technology (with reference to the specific context and nations in relation to the following aspects: Resource consumption reduction; reduction of the environmental burden; improvement of the quality of the internal environment; economical aspects; management; other factors) and of weaknesses/disadvantages of the relevant system and technology in relation to the following aspects: issues related to the architectonical integration, cultural differences (connected to the landscape perception of mainstream culture in the local context), differences in the legal framework (linked to local norms and to the presence of bureaucratic issues and similar), technical difficulties for installation/assembly linked to the local production context (lack of manufacturers, supply difficulties, economic and environmental difficulties/transport costs, lack of engineers with suitable qualification, etc.). Finally proposals to overcome the above mentioned weaknesses, also with reference to the results of the focus groups, to case-studies, to the solutions already implemented by other partners, are given.

The English abstract of each document is organised considering: the definition of guidelines according to the strengths and weaknesses highlighted in the system/ technology and to the proposed solutions; the indications to develop an action plan ("Bio-construction Action Plan") to effectively implement the proposed solutions, also by means of further research programmes and pilot projects, and indications for developing an environmental quality certification, applicable in the partner countries 
involved, making reference to the possible weaknesses highlighted in the existing models of environmental certification for the relevant system and technology.

Guidelines for action plans and quality certifications have been defined thanks to the comparison of the elements highlighted for each system/technology and for the different applications, thanks to the information provided to the Matrixes by various partners. These plans and certifications could then be considered at local level and, therefore, be implemented by single partners. Moreover, they can be used to define which actions are common to two or more partners, with the possibility to adopt common action strategies.

\section{Action Plans for Sustainable Development}

The English abstracts included in the cards elaborated for the different Partner Countries Matrixes have been organized in specific sections dealing with various themes (for instance, passive solar, photovoltaics, biomass etc.) and applications (New Constructions, Refit Works of Recent Buildings, Renovation and refit works of historical buildings and Works ex novo in historical contexts), for setting up an action plan, defined "Bio-construction Action Plan", whose aim is to lay the foundations for concretely implementing the solutions suggested in the cards, through additional research programs and pilot projects. The collected information were then analysed and compared for the elaboration of the "Bio-construction Action Plans.” It allows a fruitful exchange of information between the partners, which can be useful both for availing itself of the experience gained in the other countries, to find particularly effective solutions and to assess the opportunity to start common actions on a transnational and European level. Following some examples of the "Bioconstruction Action Plan", organized by themes with information of transnational character, are provided with the aim to give an idea of the results achieved [8].

\subsection{Passive Solar}

The attitude of the various countries about this theme differs, thus making their proposals inhomogeneous. For instance, Italy deems it appropriate to analyse the existing properties, especially in the decayed peripheral contexts, in order to carry out large scale interventions; Greece believes that it would be useful to have demonstrative and dissemination projects about the necessary technological know-how for designing passive solar systems. The latter action suggested a proposal about the SCORE project, by selecting interesting case studies and innovative technologies in order to exchange know how among the different partners. Other projects of the same kind may be of great importance. With respect to the first possible action, the necessary economic resources are high; nonetheless these studies are indispensable to assess where it is more appropriate to intervene; the energy rehabilitation of large real estates may even have very positive results and allows amortizing the costs relatively quickly. There may be different ways to perform large scale analysis of the existing buildings; this kind of operations already started within the Smartcity initiative [10], nonetheless it can be currently complex to resort to European projects funds. Rather, incentives could be offered to managing entities as tax relief or allowing them to have volumetric increases (for instance the solar greenhouses themselves), obliging them though to extensive energy rehabilitation works.

Finally, several countries such as France and Italy feel the need to have common calculation and software tools to study the passive solar systems which, actually, are not by nature system based and therefore they are less "reliable" than other energy production systems based on renewable resources.

\subsection{Small Wind Turbine}

The technologies of the mini and micro wind power are still less used compared to other production systems from renewable resources (not necessarily better); this is also true for the different partners which dealt with the topic. The substantially homogeneous situations deriving from the poor dissemination of this type of system solutions leads to single out similar actions. They essentially concern landscape and integration problems, finding environmental data (wind regime), defining a normative framework on this subject and suitable incentives. Besides the individual and important aspects, considering the reduced development of this promising technology and the substantial homogeneity of situations found in the MED countries, the theme of the mini and micro wind power seems strategic for starting specific lines of research on a European or transnational level.

\subsection{Microclimatic and Environmental Control through Vegetation}

As to this theme, there are very interesting proposals about training, normative reorganization, drafting technical standards, implementing pilot projects and operational test to assess benefits and risks. Databases about the types of employable plants with their possible effects on the microclimatic and environmental control are needed. If the shared interest for the creation of databases could imply common actions in the framework of transnational research projects, it is also true that the databases for the vegetation normally have a value as to the plants in the specific area of reference. Therefore, it would be necessary to start transnational projects in order to define the structure of the database in order then to 
implement the contents with investigations on a local scale.

\section{Summary}

The project presented demonstrates the considerable results, which can be obtained thanks to an international cooperation in the field sustainable energy policies in the construction sector on fragile coastal and rural MED areas with exceptional landscape values. Among the achieved results, special attention can be given in particular to the definition of guidelines and action plans for each partner and general action plans ("Bioconstruction action plans”). This has been possible thanks to what emerged from the work on the Matrix (Figure 3), and guarantees the diffusion and the application of energy saving solutions in the building sector and in town planning as for reference territories. Besides the definition of development and research projects that need to be implemented at local, transnational and European level through the identification of potential resources to foster such projects has been carried out, together with the identification of criteria for an environmental certification system applicable in the countries of partners involved. A key element for a wider diffusion of sustainable technology is the mutual exchange of good practices at procedural, regulatory, management and educational level, which comes from the broad communication of the results achieved by SCORE.

Another important result of the project is that a methodology has developed that seems very effective for local government interested in creating a network among themselves and with others in the area, in order to deal effectively and in a participatory way with the theme integration of sustainable building technologies and innovative solutions in areas of high landscape value.

In this historical moment the challenge of sustainability is no longer at least not only to identify the technologies and systems to be applied (there are already many, very advanced and effective), it is rather finding strate- gies for the concrete and widespread application of these technologies and systems, able to overcome the strong resistance and unfortunately still existing legal, regulatory, bureaucratic, productive, cultural and local resistances.

\section{Acknowledgements}

All the Partners of the SCORE project, the leader partner Provincia di Savona (for which the Department of Architectural Sciences of the University of Genoa has been the scientific coordination), and in particular the project manager Antonio Schizzi are acknowledged.

\section{REFERENCES}

[1] E. Wit and J. McClure, "Statistics for Microarrays: IEAECBCS,” Annual Report, 2008, p. 44.

[2] C. Thormark, "A Low Energy Building in a Life Cycle. Its Embodied Energy, Energy Need for Operation And Recycling Potential,” Building and Environment, Vol. 37, No. 4, 2002, pp. 429-435.

[3] D. Prasad and M. Hill, "The Construction Challenge: Sustainability in Developing Countries,” London Royal Institution of Chartered Surveyors (RICS) Series 2004, Leading Edge Series.

[4] E. Nuzzo and E. Tomasinsig, "Recupero Ecoefficiente del costruito,” Edicom Edizioni, Monfalcone (Gorizia) 2008.

[5] A. Giachetta "Il Progetto Ecologico Oggi: Visioni Contrapposte,” Alinea Editrice, Firenze, 2012.

[6] G. Cassinelli and A. Magliocco, "Small Energy Production Plants in Ancient Settlements: The Case Study of Camogli,” 3rd International Conference on Heritage and Sustainable Development, Porto, 19-22 Jun 2012, pp. 433-442.

[7] www.programmemed.eu

[8] www.scoremed.eu

[9] Gse, "Rapporto Statistico 2011—Fotovoltaico" www.gse.it

[10] www.genovasmartcity.it 